\title{
ELABORAÇÃO DE FERRAMENTA DE CÁLCULO PARA A DETERMINAÇÃO DO COEFICIENTE CONVECTIVO EM EXPERIMENTOS DE CONVECÇÃO FORÇADA AO REDOR DE UM CORPO SUBMERSO E ALETAS
}

\author{
TORRES, F. C. O. ${ }^{1}$, BARBOSA NETO, A. M. ${ }^{2}$ \\ ${ }^{1}$ Universidade Federal de Sergipe, Departamento de Engenharia Química \\ ${ }^{2}$ Universidade Estadual de Campinas, Faculdade de Engenharia Mecânica, Departamento de \\ Energia - Divisão de Petróleo \\ E-mail para contato: fernandocoft@yahoo.com.br
}

\begin{abstract}
RESUMO - Os processos de transferência de calor envolvendo o fenômeno de convecção natural ou forçada, têm vasta aplicação na engenharia. Em laboratórios didáticos ou de pesquisa, experimentos envolvendo sistemas de convecção forçada ao redor de corpos submersos e aletas são realizados para avaliar a troca térmica dos sistemas. Nestes experimentos deseja-se determinar o coeficiente convectivo para análise de desempenho de sistemas térmicos ou até mesmo dimensionamento de equipamentos. Diante deste contexto, o presente trabalho teve como objetivo principal desenvolver uma ferramenta de cálculo útil para o tratamento de dados experimentais de transferência de calor envolvendo convecção forçada ao redor de corpos submersos e em superfícies estendidas. Esta ferramenta é capaz de determinar o coeficiente convectivo do sistema nas condições operacionais de cada experimento. O programa foi desenvolvido em linguagem de programação Visual Basic Applications (VBA) em aplicativo Excel. $\mathrm{O}$ mesmo foi avaliado a partir de dados experimentais coletados em laboratório didático de transferência de calor. Os valores do coeficiente convectivo foram obtidos para os sistemas de convecção forçada ao redor de um corpo submerso e aletas.
\end{abstract}

\section{INTRODUÇÃO}

Segundo Çengel (2009), calor é uma forma de energia que pode ser transferida de um sistema para outro em consequência da diferença de temperatura entre eles. A ciência que estuda as taxas de energia térmica entre os corpos recebe o nome de transferência de calor.

Experimentos de transferência de calor que utilizam processos de convecção são comumente realizados em laboratório de fenômenos de transporte nos cursos de engenharia química. Dentre estes experimentos destaca-se o estudo do transporte de energia em superfícies estendidas (aletas) e convecção forçada em um cilindro submerso. Fenômenos envolvendo convecção são fortemente dependentes das propriedades do fluido, tais como viscosidade dinâmica $(\mu)$, condutividade térmica $(k)$, densidade $(\rho)$, calor específico $\left({ }^{c} p\right)$, e da velocidade do fluido $(v)$ (Holman, 1986). Além destes fatores, a geometria e a rugosidade da 
superfície sólida e o regime de escoamento (laminar ou turbulento) influenciam na transferência de calor por convecção.

A determinação do coeficiente convectivo é de fundamental importância em experimentos de aletas e convecção forçada, pois implica na avaliação da taxa de transferência de calor por convecção (Kern, 1999). Desta forma, torna-se possível avaliar as condições nas quais ocorre aumento da taxa de transferência de calor por convecção. Além disso, permite determinar o tipo de convecção que está ocorrendo no estudo experimental (Incropera et al. 2008).

Diante deste contexto, o objetivo do presente trabalho foi desenvolver uma ferramenta de cálculo capaz de determinar o coeficiente convectivo a partir de dados experimentais de convecção forçada ao redor de um corpo submerso e aletas.

\section{METODOLOGIA}

Uma ferramenta de cálculo, desenvolvida em linguagem de programação Visual Basic for Applications (VBA) em aplicativo Excel, foi desenvolvida para o tratamento dos dados obtidos em experimentos de convecção forçada e superfícies estendidas. Para utilizar a ferramenta faz-se necessário alimentar uma planilha com os dados experimentais coletados em laboratório. A seguir são descritas as metodologias de cálculo implementadas para cada experimento no programa desenvolvido.

\subsection{Convecção Forçada ao Redor de um Corpo Submerso}

A partir dos dados de entrada, tais como, temperatura da superfície $\left({ }^{T} c p\right)$ e temperatura do ar $\left({ }^{T_{\infty}}\right)$, determina-se a temperatura de filme $\left({ }^{T_{f}}\right)$ utilizando a Equação 1:

$$
T_{f}=\frac{T_{c p}+T_{\infty}}{2}
$$

A rotina de cálculo do programa começa a ser implementada para fornecer a temperatura de filme para cada temperatura medida, nas posições determinadas previamente, fornecendo a mesma já em Kelvin. Outra variável relevante no experimento é a velocidade do fluido de resfriamento, sendo esta calculada através de uma média aritmética simples, uma vez que a medição da velocidade de escoamento do fluido é realizada em quatro posições distintas.

Em posse da temperatura de filme determina-se as propriedades físicas, tais como, viscosidade e condutividade térmica, por exemplo. É feita a imposição de um fluxo constante sobre a superfície que troca calor com ambiente por meio da convecção. Uma maneira simples é ocasionar um aquecimento elétrico do cilindro e realizar medições da temperatura da superfície e do fluido, bem como da potência dissipada pelo aquecimento do cilindro. Logo, sabe-se que:

$$
P=U I
$$


Na Equação (2), $P$ é a potência de aquecimento, $U$ é a tensão do sistema elétrico e $I$ é a corrente elétrica que percorre o resistor.

Como a taxa de aquecimento elétrico é igual à taxa de resfriamento por convecção na superfície do cilindro, tem-se que:

$$
P=U I=h A\left(T_{s}-T_{\infty}\right)=Q
$$

É importante ressaltar a praticidade deste programa, que uma vez a planilha alimentada com os dados de entrada, e com as condições experimentais especificadas obtém de maneira rápida as propriedades físicas do ar implicando assim na determinação do coeficiente convectivo local, que é o objetivo do experimento em análise.

Outra vantagem da utilização deste programa é a obtenção das propriedades físicas do fluido, já que dificilmente se encontra na literatura estas propriedades nas temperaturas requeridas, logo foi criado um banco de dados contendo as propriedades físicas relevantes para esta prática, viscosidade, condutividade térmica do material que constitui o cilindro, por exemplo, com uma faixa de temperatura, de 200 à $550 \mathrm{~K}$.

Uma sub-rotina de interpolação dos dados foi implementada na ferramenta para que se possa obter o valor de cada propriedade física em uma temperatura específica. Em posse dos dados experimentais, coletados na prática além de obter as propriedades físicas do fluido de escoamento, utilizando o banco dados do programa, obtém-se de maneira prática e rápida o coeficiente convectivo de transferência de calor.

\subsection{Aletas}

No experimento de aletas, são disponibilizadas quatro barras de materiais distintos, Aço Inox (Barra $A, D_{i}=25 \mathrm{~mm}$ ), Aço Inox (Barra B, $D_{i}=13 \mathrm{~mm}$ ), Alumínio (Barra $\mathrm{C}, D_{i}=13 \mathrm{~mm}$ ), e Cobre (Barra D, ${ }^{D_{i}}=13 \mathrm{~mm}$. Além disso, termopares são distribuídos para análise do perfil de temperatura ao longo da barra.

Através da análise dos dados experimentais possíveis de serem coletados fez-se duas considerações: sistema formado por aletas infinitas e aletas com temperatura especificada na ponta.

Segundo Incropera (2008), para aletas consideradas infinitas e com temperatura especificadas na ponta da barra pode-se utilizar as seguintes equações respectivamente:

$$
\begin{aligned}
\frac{\Theta}{\Theta_{b}} & =\frac{T(x)-T_{\infty}}{T_{b}-T_{\infty}}=e^{-m x} \\
\frac{\Theta}{\Theta_{b}} & =\frac{\cosh \mathrm{m}(\mathrm{L}-\mathrm{x})+(h / m k) \operatorname{senh} m(L-x)}{\cosh m L+(h / m k) \operatorname{senh} m L}
\end{aligned}
$$


Nota-se que a Equação (4) é não linear, então para a determinação do parâmetro $m$, foi utilizado o método numérico Newton-Raphson. Para que este método pudesse ser implementado fez-se necessário calcular a diferencial analítica da Equação (5).

Então, através da Equação (2) ou (5) determina-se o valor do parâmetro $m$, e consequentemente o valor do coeficiente convectivo, utilizando Equação (6).

$m^{2}=\frac{2 h}{k r}$

Novamente, a ferramenta desenvolvida mostra-se de fácil manuseio para o usuário e, possibilita também selecionar o tipo de barra utilizada. Desta forma, o usuário obtém os resultados de cada experimento de maneira prática e rápida.

\section{RESULTADOS E DISCUSSÕES}

Em relação ao experimento de convecção forçada ao redor de um cilindro, com comprimento de $200 \mathrm{~mm}$ e com um diâmetro de $44 \mathrm{~mm}$, os dados experimentais, mostrados na Tabela 1, foram alimentados na ferramenta de cálculo desenvolvida.

Tabela 1 - Dados de entrada.

\begin{tabular}{ccccc}
\hline Propriedades & Voltagem $(\mathrm{U})$ & Corrente $(\mathrm{A})$ & $\begin{array}{c}\text { Diâmetro } \\
\text { Externo }(\mathrm{mm})\end{array}$ & $\begin{array}{c}\text { Temperatura } \\
\text { do } \operatorname{ar}\left({ }^{\circ} \mathrm{C}\right)\end{array}$ \\
\hline Valores & 100,0 & 0,6 & 44,0 & 25,7 \\
\hline
\end{tabular}

Os valores coletados de temperatura na superfície do cilindro $\left(\mathrm{T}_{\mathrm{cp}}\right)$, em várias posições (L), parametrizada na velocidade de escoamento do fluido são apresentados na Tabela 2.

Tabela 2 - Temperatura do cilindro para as três velocidades de escoamento do fluido.

\begin{tabular}{cccc}
\hline \multirow{2}{*}{$L(\mathrm{~mm})$} & \multicolumn{3}{c}{$T_{c p}\left({ }^{\circ} \mathrm{C}\right)$} \\
\cline { 2 - 4 } & $v_{1}=1,052 \mathrm{~m} / \mathrm{s}$ & $v_{2}=3,325 \mathrm{~m} / \mathrm{s}$ & $v_{3}=4,075 \mathrm{~m} / \mathrm{s}$ \\
\hline-80 & 94 & 70 & 64 \\
-60 & 95 & 71 & 65 \\
-40 & 94 & 71 & 66 \\
-20 & 95 & 71 & 67 \\
0 & 93 & 70 & 66 \\
20 & 93 & 70 & 66 \\
40 & 93 & 70 & 66 \\
60 & 94 & 70 & 66 \\
80 & 92 & 69 & 65 \\
\hline
\end{tabular}

Os coeficientes de películas determinados utilizando a ferramenta de cálculo são apresentados em função da velocidade de escoamento do fluido na Figura 1.

Figura 1: Relação entre o coeficiente convectivo médio com a velocidade de escoamento do fluido. 


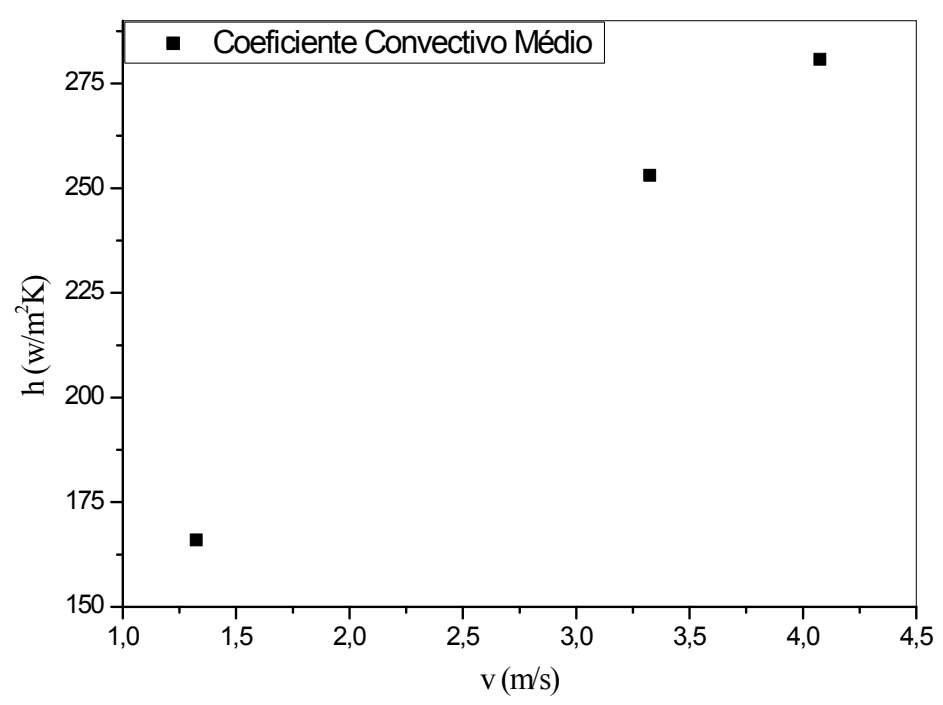

Em relação ao experimento de superfícies estendida, os dados alimentados ao programa são mostrados na Tabela 3.

Tabela 3 - Valores de temperatura obtidos através da leitura de termopares em função de suas posições, para $T_{\infty}=26^{\circ} \mathrm{C}$.

\begin{tabular}{ccc}
\hline $\begin{array}{l}\text { Posição dos termopares } \\
\text { ao longo da barra }(\mathrm{mm})\end{array}$ & \multicolumn{2}{c}{$\begin{array}{c}\text { Temperaturas na barra D } \\
\left({ }^{\circ} \mathrm{C}\right) \text { para } \mathrm{T}_{\mathrm{q}}=79,5^{\circ} \mathrm{C} \mathrm{D}\end{array}$} \\
\hline T1 & 50 & 59 \\
T2 & 100 & 54 \\
T3 & 150 & 51 \\
T4 & 250 & 43 \\
T5 & 350 & 39 \\
T6 & 450 & 36 \\
T7 & 600 & 34 \\
T8 & 750 & 31 \\
T9 & 900 & 29 \\
T10 & 1150 & 28 \\
\hline
\end{tabular}

Os coeficientes convectivos locais calculados para uma temperatura de fonte quente de $79,5^{\circ} \mathrm{C}$, utilizando a barra D são apresentados na Figura 2.

Figura 2: Coeficiente convectivo em função da posição dos termopares. 

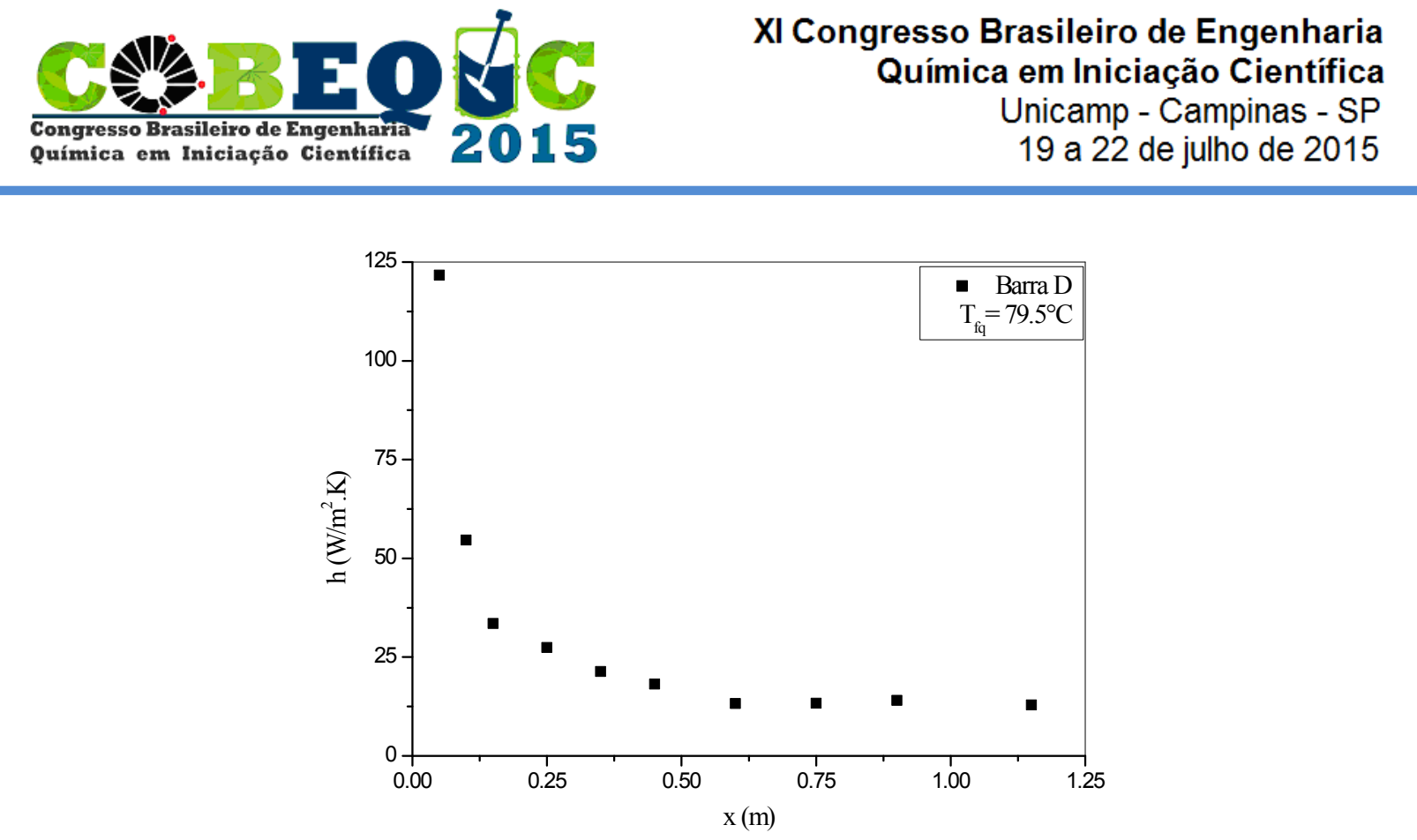

Analisando a Figura 2 nota-se que a medida que se distancia da fonte de aquecimento o coeficiente de película diminui implicando em menores taxas de transferência de calor por convecção.

\section{CONCLUSÃO}

De acordo com os resultados apresentados conclui-se que a ferramenta de cálculo elaborada é capaz de determinar o coeficiente de convecção forçada a partir dos dados experimentais de ensaios de superfícies estendidas e convecção forçada ao redor de corpos submersos. Além disso, a ferramenta mostrou-se de fácil manuseio e prática para ser utilizada no meio acadêmico.

\section{REFERÊNCIAS}

ÇENGEL, Y. A. Transferência de Calor e Massa: Uma Abordagem Prática. São Paulo: McGraw-Hill, 2009, $3^{\text {a }}$ ed.

HOLMAN, J. P. Heat Transfer. Singapore: McGraw-Hill, 1986, 6ª ed.

INCROPERA, F. P.; DEWITT, D. P.; Bergman, T. L.; Lavine, A. S. Fundamentos de transferência de calor e de massa. Rio de Janeiro: LTC, 2008, 6a ed., 645p.

KERN, D. Q. Process Heat Transfer. San Juan Tlihuaca: McGraw-Hill, 1999, $30^{\mathrm{a}}$ ed. 